\title{
Application and Research of New Monitor AGC in Hot Strip Mill
}

\author{
Bingkui Wang ${ }^{a}$, Ce Wang ${ }^{b}$, Ziying Liu ${ }^{c}$, Xudong Li ${ }^{d}$ \\ Shougang Research Institute of Technology, Beijing 100043, China. \\ awangbingkui456@163.com, bwangce_2012@163.com, 'czoonlzy@163.com, \\ dlixudonggo@163.com
}

\begin{abstract}
A Monitor AGC control system is applied to a hot strip mill in a steel plant, due to some irrationality gain factors and the hysteresis of the Monitor AGC control output, the strip thickness deviation is large. This paper designs a new type Monitor AGC that includes two control methods:Integral type Monitor AGC and Smith's method Monitor AGC, they are able to select alternately. The experimental results show that the effect of Integral type Monitor AGC and Smith's method Monitor AGC is obvious, and the accuracy of thickness control is obviously improved.
\end{abstract}

Keywords: Monitor AGC, Integral type, Smith's method, hot strip mill, thickness deviation.

\section{Introduction}

The Monitor AGC (M-AGC) refers to precise measurement of the finish mill delivery thickness of the strip by means of X-ray thickness gauge and the result is applied as a gap correction to the Gap Control for each stand [1]. X-ray Monitor defaults to Absolute and will produce gap corrections to make the strip thickness equal the X-ray gage target thickness (zero deviation).

The indirect thickness control system based on the bounce equation considers various compensation factors (roll bending deformation compensation, roller roll crown compensation, oil film compensation, roll thermal expansion compensation, etc.), but its thickness measurement accuracy is much lower than X-ray thickness gauge, therefore, M-AGC is indispensable for modern strip hot rolling.

\section{Integral Type Monitor AGC}

The X-ray Monitor regulator uses integral control to eliminate steady state errors. The regulator provides independent control of the correction to each stand to allow fast response for the head of the strip with a means to control overshoot and a scheme to balance monitor corrections among stands. Figure Fig. 1 is an overview of the X-ray Monitor Function.

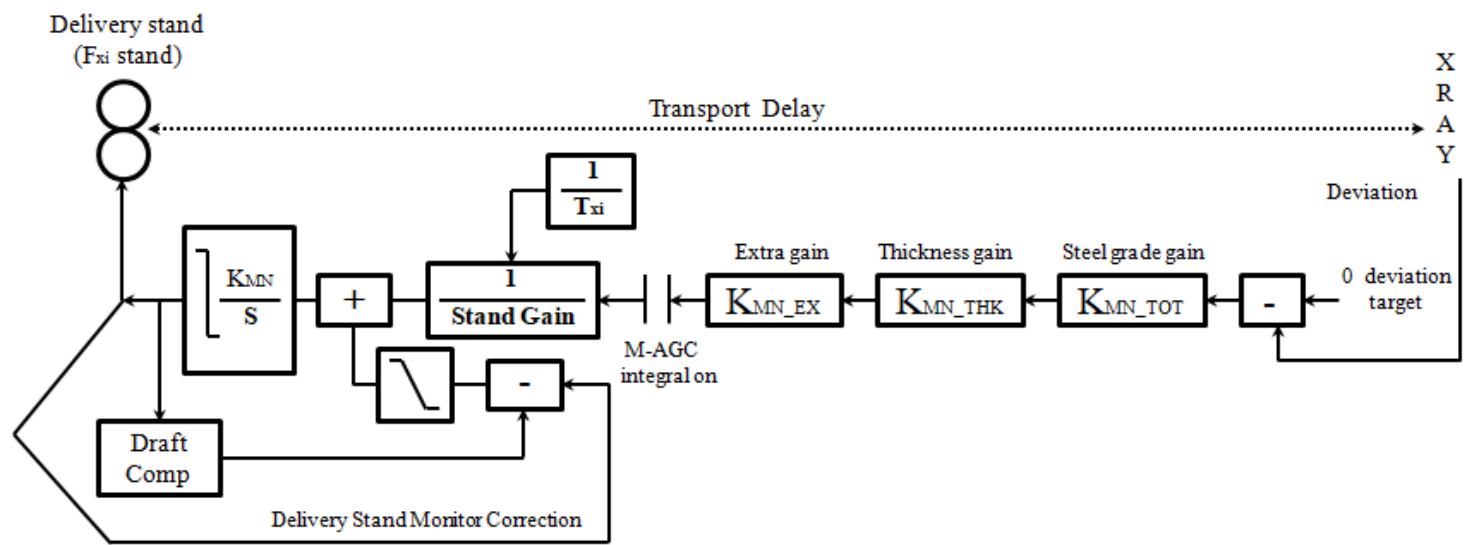

Fig. 1 X-ray Monitor Block Diagram

The regulator for the delivery stand can act the quickest because the delivery stand is closest to the $\mathrm{X}$-ray gage. However, all correction cannot be applied by the delivery stand because of power, load distribution and shape considerations [2-4]. Therefore, the X-ray Monitor control will make a correction at the delivery stand quickly and gradually add correction upstream to distribute the load to other stands. 


\subsection{Calculation of Gain.}

Experience has proven that stability of the X-ray Monitor control varies with strip thickness. A higher gain can be tolerated when rolling heavier gage. Therefore, the gain (КМN_Tот) for all stands is modified based on the X-ray gage target thickness. This gain (KMN_TOT) is also modified based on the steel grade classify.

$$
K_{M N \_T O T}=K_{H} \times K_{G} \times K_{C}
$$

where, $\mathrm{K}_{\mathrm{MN}}$ тот is the $\mathrm{F}_{\mathrm{xi}} \mathrm{M}-\mathrm{AGC}$ total gain (-). $\mathrm{K}_{\mathrm{H}}$ is the HI-B steel grade correction (-), and different steel grade family, different values. $\mathrm{K}_{\mathrm{G}}$ is the steel grade gain (-). $\mathrm{K}_{\mathrm{C}}$ is the M-AGC stand $\left(\mathrm{F}_{\mathrm{xk}}, \mathrm{F}_{\mathrm{xk}-1}\right.$ or $\left.\mathrm{F}_{\mathrm{xk}-2}\right)$ change gain.

The gain $\left(\mathrm{K}_{\mathrm{THK}}\right)$ modifier related to product thickness is created by linear interpolation between gains for target thickness.

$$
K_{T H K}=\left(h_{e x t}-X_{n-1}\right) \frac{Y_{n}-Y_{n-1}}{X_{n}-X_{n-1}}+Y_{n-1}
$$

where, $\mathrm{K}_{\mathrm{THK}}$ is $\mathrm{F}_{\mathrm{k}} \mathrm{M}$-AGC thickness gain, hext is last stand delivery thickness $(\mathrm{mm}), \mathrm{F}_{\mathrm{k}} \mathrm{M}$-AGC thickness gain table $\mathrm{X}(-)$ and $\mathrm{Y}(-)$ are shown as below.

Table 1.Fk M-AGC Thickness Gain Table

\begin{tabular}{lccc}
\hline F $_{\mathbf{k}}$ M-AGC THICKNESS GAIN TABLE X(-) & F $_{\mathbf{k}}$ M-AGC THICKNESS GAIN TABLE Y(-) \\
\hline if & $X_{0}=1.2$ & then & $Y_{0}=0.60$ \\
if & $X_{1}=1.6$ & then & $Y_{1}=0.65$ \\
if & $X_{2}=2.0$ & then & $Y_{2}=0.68$ \\
if & $X_{3}=2.5$ & then & $Y_{3}=0.70$ \\
if & $X_{4}=3.0$ & then & $Y_{4}=0.75$ \\
if & $X_{5}=4.0$ & then & $Y_{5}=0.80$ \\
if & $X_{6}=5.0$ & then & $Y_{6}=0.80$ \\
if & $X_{7}=6.5$ & then & $Y_{7}=0.80$ \\
if & $X_{8}=11.0$ & then & $Y_{8}=0.80$ \\
if & $X_{9}=14.0$ & then & $Y_{9}=0.80$ \\
\hline
\end{tabular}

The X-ray Monitor Gain for all stands is increased when the error is excessively large. When the error is large the gain can be increased to try to bring the strip on gage more quickly and then returned to a level that will not cause excessive overshoot. The level at which the extra gain is applied and the amount of extra gain are adjustable to allow coordination with the limits of the Loopers ability to maintain mass flow.

$$
K_{M N_{-} X G A I N}=\left\{\begin{array}{ll}
1.55 & 7 \leq h<+\infty \\
1.45 & 3 \leq h<7 \\
1.35 & 2 \leq h<3 \\
1.35 & 0 \leq h<2
\end{array} \quad K_{M N_{-} E X}= \begin{cases}1.0 & \Delta h<l_{j} \\
K_{M N_{-} X G A I N} & \Delta h \geq l_{j}-l_{d} \\
1.0 & \Delta h<l_{j}-l_{d}\end{cases}\right.
$$

Where, KMN_XGAIN is monitor extra gain (-), KMN_EX is M-AGC selected extra gain (pu), $\triangle \mathrm{h}$ is $\mathrm{M}$ AGC error from deviation reference $(\mathrm{mm}), l_{j}(j=1,2)$ is monitor extra gain error level $(\mathrm{mm}), l_{1}=0.02$ in $5 \mathrm{~s}$ after opening, $l_{2}=0.04$ after opening $5 \mathrm{~s}, l_{d}\left(l_{d}=0.01\right)$ is monitor extra gain error level dead band $(\mathrm{mm})$.

\subsection{Effects of Transport Delay.}

The regulator gain for each stand determines the rate at which that regulator can correct. The gain is limited by the transport time from the correction of the strip at the stand until the effect of that correction is measured by the X-ray gage. The gain must be reduced as transport time increases.

$$
T_{X i}=\sum_{i=j}^{k-1} \frac{L_{i}}{\left(1+f_{i}\right) \cdot V_{R i}}+\frac{L_{X k}}{\left(1+f_{k}\right) \cdot V_{R k}} \quad 1 \leq \mathrm{i} \leq k \quad \mathrm{k} \text { is final control stand }
$$


where, Txi is No. i stand $\sim \mathrm{X}$-ray transport time $(\mathrm{sec}), 1 \leq \mathrm{i} \leq \mathrm{k}, \mathrm{k}$ is final control stand; $\mathrm{L}_{\mathrm{i}}$ is No. $\mathrm{i}$ to No. $i+1$ stands distance $(m)$; $f_{i}$ is No. i stand forward slip ratio (-); VRi is No. i stand roll peripheral speed $(\mathrm{m} / \mathrm{s})$; LXk is final control stand $\sim$ X-ray distance $(\mathrm{m}) ; \mathrm{f}_{\mathrm{k}}$ is final control stand forward slip ratio $(-) ; V_{R k}$ is final control stand roll peripheral speed $(\mathrm{m} / \mathrm{s})$.

$\mathrm{M}-\mathrm{AGC}$ control output $\Delta \mathrm{S}_{\mathrm{MN} \_\mathrm{AGC}}$ is within limit. If $\Delta \mathrm{S}_{\mathrm{MN} \_\mathrm{AGC}}$ is over limit, $\mathrm{M}-\mathrm{AGC}$ control output is held.

$$
-\Delta S_{L M_{-} M N_{-} A G C} \leq \Delta S_{M N_{-} A G C} \leq \Delta S_{L M_{-} M N_{-} A G C}
$$

$\Delta \mathrm{S}_{\mathrm{LM} \_ \text {MN_AGC }}=0.5 \mathrm{~mm}$.

\section{Smith's Method Monitor AGC}

Smith's method Monitor AGC get rid of offset error between final stand's gage-meter thickness and Finishing mill delivery side X-Ray strip thickness. Smith's method Monitor AGC works with ABS-GM-AGC, and works as gage-meter thickness correction for ABS-GM-AGC. Smith's method Monitor AGC and Integral type Monitor AGC are able to select alternately. Smith's method Monitor AGC block diagram is shown as below.

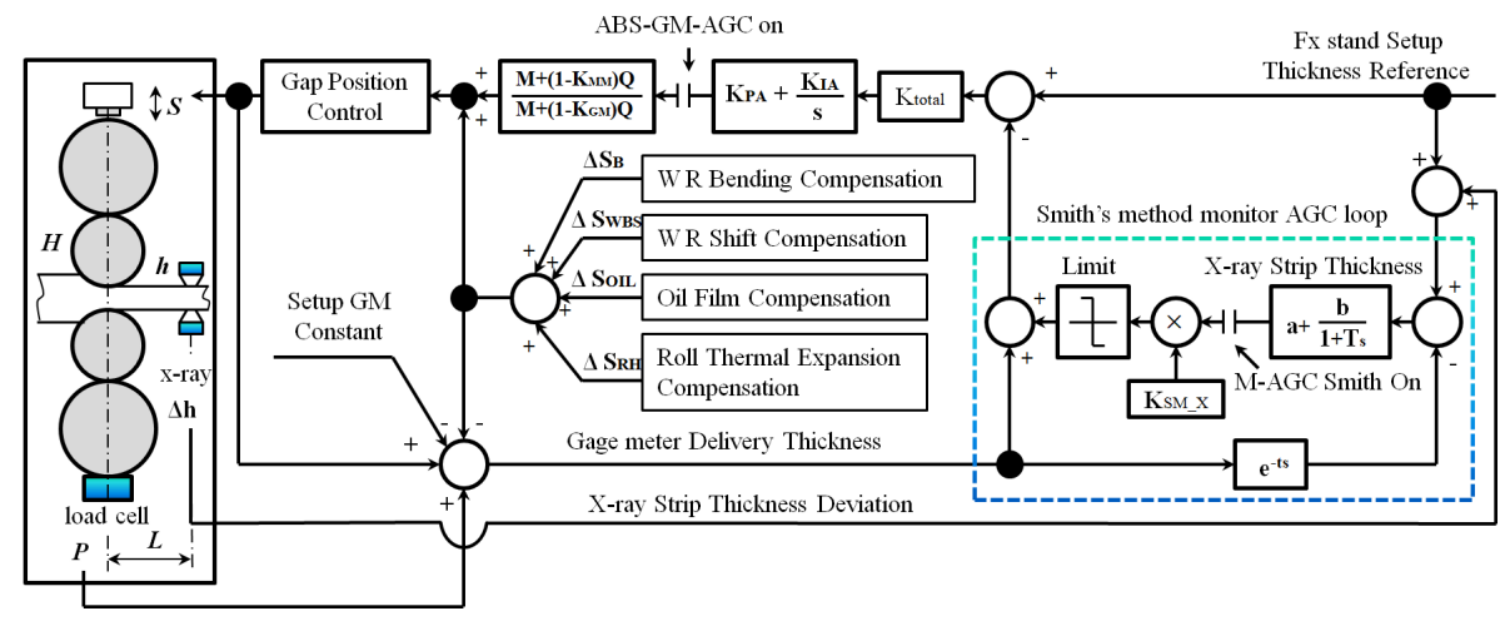

Fig. 2 Smith's method Monitor AGC block diagram

\subsection{Calculation of Gain.}

In Smith's method Monitor AGC loop block, the KSM_i is upstream stand distribution gain (-); Ts is main scan time (sec); $a$ and $b$ is constant; $\mathrm{e}^{- \text {ts }}$ is the lagging link [5].

$$
K_{S M_{-} i}=\frac{P_{S E T_{-} F i}}{P_{S E T_{-} F x}} \times K_{S M A D J_{-} i}
$$

where PSET_Fi is $F_{i}$ stand predict force $(\mathrm{kN})$; PSET_Fx is last stand predict force $(\mathrm{kN})$; KSMADJ_i is adjust gain (-).

The $\mathrm{K}_{\text {total }}$ is compensation gain (-); $\mathrm{K}_{\mathrm{PA}}$ is proportional gain (-); $\mathrm{K}_{\mathrm{IA}}$ is integral gain (-) ; $\mathrm{M}$ is mill modulus $(\mathrm{kN} / \mathrm{mm})$, (calculated by Level based on mill modulus curve equation and actual force); $\mathrm{Q}$ is plasticity coefficient(strip hardness) $(\mathrm{kN} / \mathrm{mm})$ (set by FSUC); KGM_LK is gage meter gain for LKON-GM-AGC (-) (constant gain $\times$ strip hardness gain); $\mathrm{K}_{M M}$ is MMC gain (-), when ABS-GMAGC on: $\mathrm{K}_{\mathrm{GM}}=1.0$, when LKON-GM-AGC on: $\mathrm{K}_{\mathrm{GM}}=\mathrm{K}_{\mathrm{GM}} \mathrm{LK}$ when MMC off: $\mathrm{K}_{\mathrm{MM}}=0.0$.

\subsection{Application of Smith's Method Monitor AGC.}

Smith's method Monitor AGC correction is distributed to upstream stand AGC to prevent the load unbalance [6]. Smith's method Monitor AGC block diagram for each stand is shown as below. 


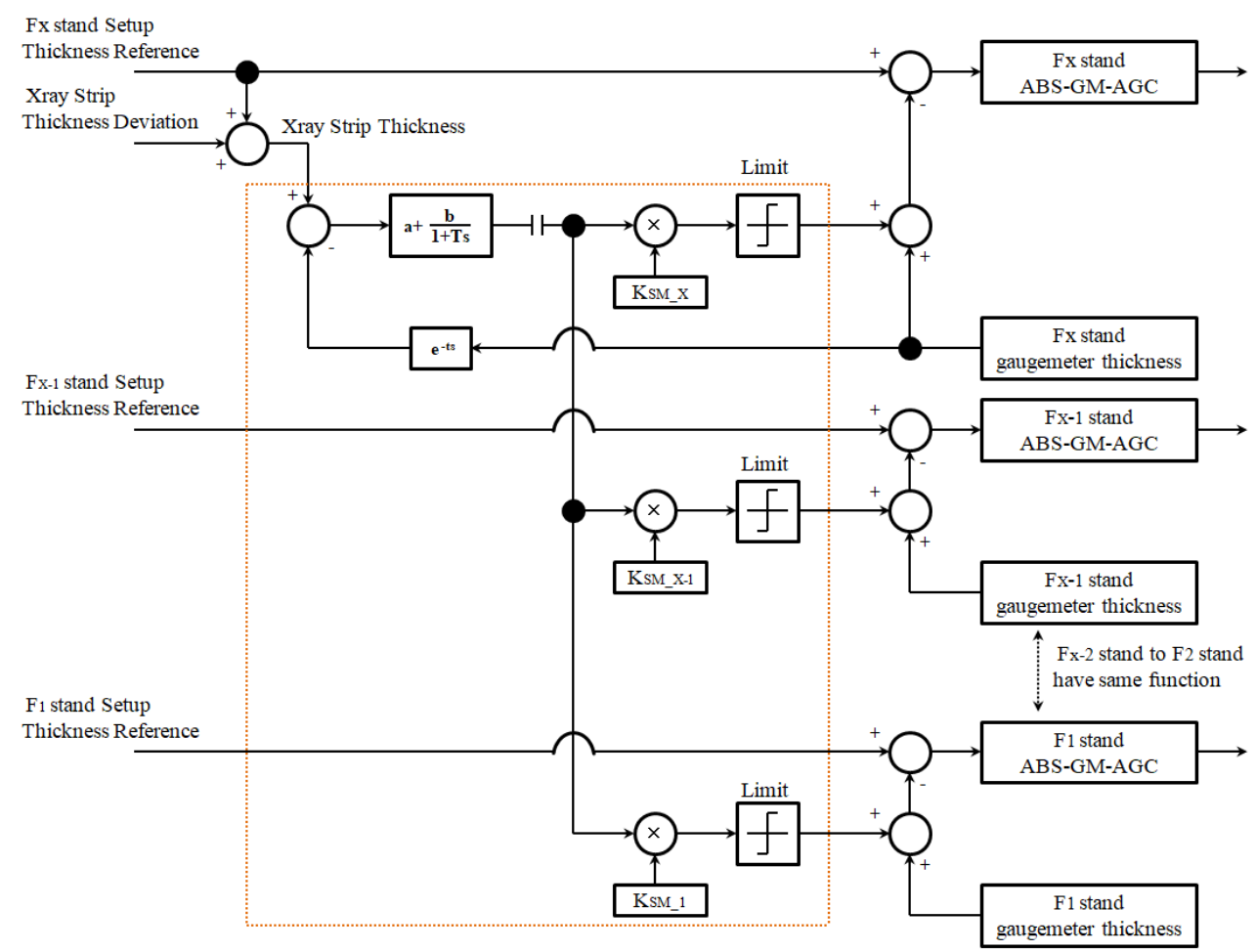

Fig. 3 Smith's method Monitor AGC block diagram for each stand

Switching between Smith's method Monitor AGC and Integral-type M-AGC.

If $\mathrm{V}_{\mathrm{P}} \leq \mathrm{V}_{\text {limit(L) }}$ is realized during Integral-type M-AGC is executing, Integral-type M-AGC stops, Smith's method starts, where $V_{P}$ is $F_{k}$ delivery speed, $V_{\text {limit }(\mathrm{L})}$ is M-AGC changing speed lower limit.

If $\mathrm{V}_{\mathrm{P}} \geq \mathrm{V}_{\text {limit(}(\mathrm{U})}$ is realized during Smith's method is executing, Smith's method stops and Integral type M-AGC starts, where $\mathrm{V}_{\text {limit(U) }}$ is M-AGC changing speed upper limit.

Smith's method Monitor AGC control output $\Delta$ SSM_AGC is within limit. If $\Delta \mathrm{SSM}_{\mathrm{S}} \mathrm{AGC}$ is over limit, Smith's method Monitor AGC control output is held.

$$
-\Delta S_{L I_{-} S M_{-} A G C} \leq \Delta S_{S M_{-} A G C} \leq \Delta S_{U P_{-} S M_{-} A G C}
$$

For $F_{K}, F_{K-1}, F_{K-2}$ stands $\Delta S_{\text {LM_MN_AGC }}=0.5 \mathrm{~mm}, \Delta$ SUP_MN_AGC $_{-}=0.6 \mathrm{~mm}$. For upstream $\Delta$ SLM_MN_AGC $=\Delta$ SUP_MN_AGC $=0.5 \mathrm{~mm}$.

The new Monitor AGC was tested on the machine. Without removing the head and tail of the strip, the thickness difference of each 100-volume strip before and after using the new Monitor AGC was calculated. Taking silicon steel S30-Y as an example, the specification of the 200-volume strip is $2.6 \mathrm{~mm} \times 1222 \mathrm{~mm}$. The statistical results are shown as below.

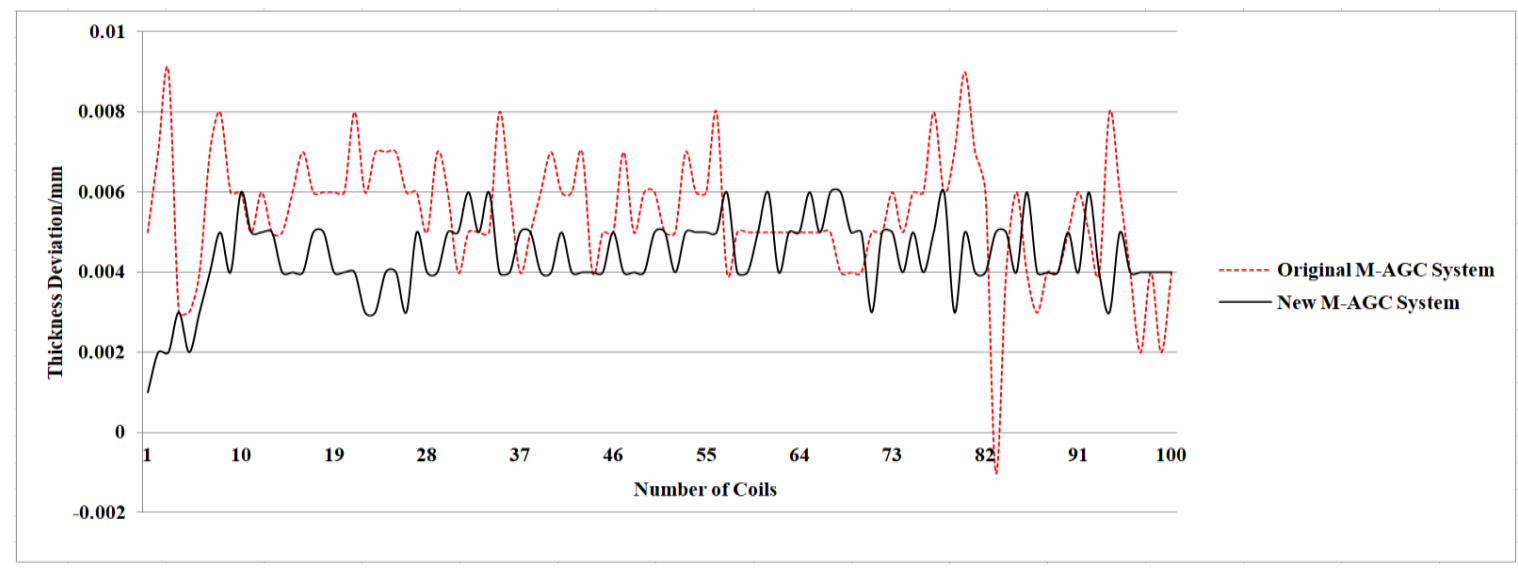

Fig. 4 Statistical results of thickness difference 


\section{Conclusion}

Monitor AGC has a strong function, if the model error is larger; Monitor AGC plays a decisive role in the control effect of thickness precision. Two kinds of control methods for Monitor AGC are designed: Integral type Monitor AGC and Smith's method Monitor AGC, they are able to select alternately according to needs. The practical application shows that the new Monitor AGC system has good stability and control precision. The delivery actual thickness deviation can be controlled within or below $\pm 0.006 \mathrm{~mm}$.

\section{References}

[1]. SUN Jie,ZHANG Dianhua,LI Xu, et al. Smith Prediction Monitor AGC System Based on Fuzzy Self-Tuning PID Control [J]. Journal of Iron and Steel Research, International. 2010, 17(2): 2226.

[2]. LI Dong, LIU Jianchang, TAN Shubin, et al. Improved Calculation on Thickness Deviation Distribution Coefficients of a New Monitor AGC[J].Information and Control. 2015,44(04): 442 -448 .

[3]. ZHANG Hao-yu, SUN Jie, ZHANG Dian-hua, et al. Improved Smith prediction monitoring AGC system based on feedback-assisted iterative learning control[J]. Journal of Central South niversity, 2014,21(09):3492-3497.

[4]. LI Dong. A New Monitor-AGC System in Hot Continues Rolling[A]. Technical Committee on Control Theory, China Association of Automation,Systems Engineering Society of China. The 33th chinese control conference Papers (D) [C]. Technical Committee on Control Theory, China Association of Automation,Systems Engineering Society of China:, 2014:5.

[5]. TAN Shubin, BAO Mingwei, LIU Jianchang. Research on Application of SmithPredictor to Monitor AGC in Hot Strip Rolling Mills[A]. Northeastern University, China,IEEE Industrial Electronics (IE) Chapter, Singapore,Guilin University of Electronic Technology, China.2009 CCDC(3) [C]. Northeastern University, China,IEEE Industrial Electronics (IE) Chapter, Singapore, Guilin University of Electronic Technology, China:, 2009:4.

[6]. LIU Jianchang, Gu Shusheng, ZHENG Shifu, et al. Application of Smith Predidiction Control Strategy to AGC System[J]. Iron and Steel,1998(10):42-45. 